\title{
Place of Radiotherapy in Multimodal Treatment of High-Risk Neuroblastoma: Through A Report Case
}

\author{
A. Bazine ${ }^{1,2,3,4^{*}}$, O. Ait Sahel ${ }^{5}$, M. Elmarjany ${ }^{1}$, M. Benlemlih ${ }^{1}$, A. Maghous ${ }^{1}$, A. Marnouche ${ }^{1}$, M. Houmadi ${ }^{1}$, KH. \\ Andaloussi ${ }^{1}$, KH. Haddadi ${ }^{1}$, H. Sifat ${ }^{1}$, H. Mansouri ${ }^{1}$
}

\author{
${ }^{1}$ Radiotherapy department of Military Instruction Hospital Mohamed V, Rabat, Morocco \\ ${ }^{2}$ Faculty of Medicine and Pharmacy, Fez, Morocco \\ ${ }^{3}$ Sidi Mohamed Ben Abdellah University, Fez, Morocco \\ ${ }^{4}$ Mohamed V University, Rabat, Morocco \\ ${ }^{5}$ Nuclear Medicine departments of Military Instruction Hospital Mohamed V, Rabat, Morocco
}

DOI: $10.36347 /$ sasjm.2020.v06i12.006

| Received: 11.12.2020 | Accepted: 21.12.2020 | Published: 29.12.2020

*Corresponding author: A. Bazine

Abstract

Case Report

Neuroblastoma is the most common extracranial solid tumor in children. One subset, high-risk neuroblastoma, is very difficult to treat and requires multi-modal therapy and radiation therapy, alongside surgery, is one of means to ensure local control of disease. We report in this work, the case of 5-year-old girl presenting a high risk neuroblastoma, having benefited from a multimodal therapeutic approach. Through this report case, we will discuss the place of radiotherapy in this treatment strategy, we will describe the various technical aspects of this radiotherapy and we will shed light on the main points of discussion that persist.

Keywords: Neuroblastoma, high risk, multimodal treatment, radiation therapy.

Copyright $\odot 2020$ The Author(s): This is an open-access article distributed under the terms of the Creative Commons Attribution 4.0 International License (CC BY-NC 4.0) which permits unrestricted use, distribution, and reproduction in any medium for non-commercial use provided the original author and source are credited.

\section{INTRODUCTION}

Treatment of high-risk neuroblastoma involves induction chemotherapy, surgical resection, local radiation therapy, and maintenance therapy. This aggressive multi-modality program has improved outcomes, but entails major acute and long-term toxicities. Currently radiation therapy has a major place in the local treatment of high-risk neuroblastoma. We report in this work, the case of 5-year-old girl presenting a high risk neuroblastoma, having benefited from a multimodal therapeutic approach. Through this report case, we will discuss the place of radiotherapy in this treatment strategy, we will describe the various technical aspects of this radiotherapy and we will shed light on the main points of discussion that persist.

\section{CASE REPORT}

This is a 5-year-old girl who presented in October 2015 with an increase in abdominal volume associated with diffuse bone pain. An abdominal computed tomography (CT) scan showed a large mass at the expense of the left adrenal gland, pushing the left kidney downwards (Figure-1). Biopsy returned in favor of a moderately differentiated adrenal neuroblastoma. Test for amplification of the N-MYC gene came back positive. Bone marrow biopsy revealed the presence of medullary invasion by a poorly differentiated neuroblastoma. Meta-iodo-benzyl-guanidine (MIBG) scan returned in favor of secondary bony localizations in skull, both shoulders, sternum and dorsal and lumbar spine. Biologically, level of lacticodehydrogenase (LDH) was normal at $326 \mathrm{IU} / \mathrm{ml}$. 


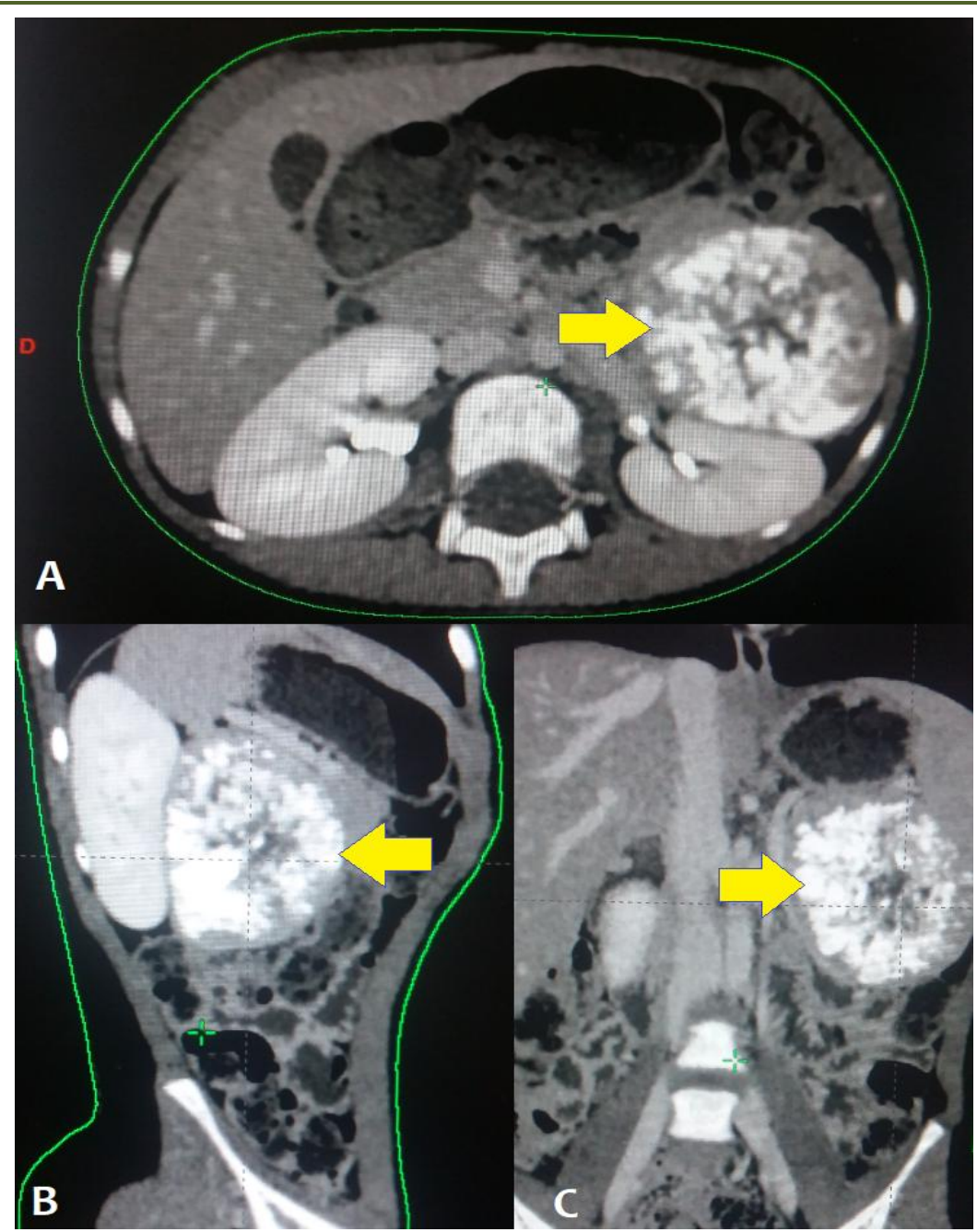

Fig-1: Abdominal CT scan in axial slices (A) with sagittal (B) and coronal (C) reconstruction, showed a large mass at the expense of the left adrenal gland, pushing the left kidney downwards

The disease has been classified according to the International Neuroblastoma Risk Group (INRG) [1, 2] as a high risk neuroblastoma.

Patient received 05 cycles of induction chemotherapy according to Pediatric Oncology Group protocol 9341 [3]. Evaluation, made after induction chemotherapy, showed a tumor reduction of approximately $80 \%$ with absence of bone marrow invasion on bone marrow biopsy and persistence of bone metastatic foci on the MIBG scan. In April 2016, the child underwent a total macroscopic resection (GTR) of residual disease. Pathological examination showed an $11 \mathrm{~cm}$ fragment of a mixed ganglioneuroblastoma in its favorable form. An autologous transplant of hematopoietic stem cells was performed after consolidation chemotherapy according to $\mathrm{Bu}-\mathrm{Mel}$ protocol combining Busulfan and Melphalan [3].

The child was referred in October 2016 for local radiotherapy as part of his consolidation treatment.
First examination was unremarkable except for a scar from left subcostal laparotomy.

A simulation computed tomography scanner with injection of contrast product was performed with a thorax support, with both hands above head, allowing the two upper limbs to be released from the trunk.

On a treatment planning system, a registration with initial imaging (scanner before induction chemotherapy) was performed (Figure-2). Then, a delineation of target volumes and organs at risk was carried out. Clinical target volume (CTV) corresponds to the initial macroscopic volume, before induction chemotherapy. Planning target volume (PTV) corresponds to CTV with a margin around $1.5 \mathrm{~cm}$ (Figure-3). Delineation makes it possible to obtain a three-dimensional reconstruction of the different volumes of interest, which will facilitate definition of treatment ballistics. 


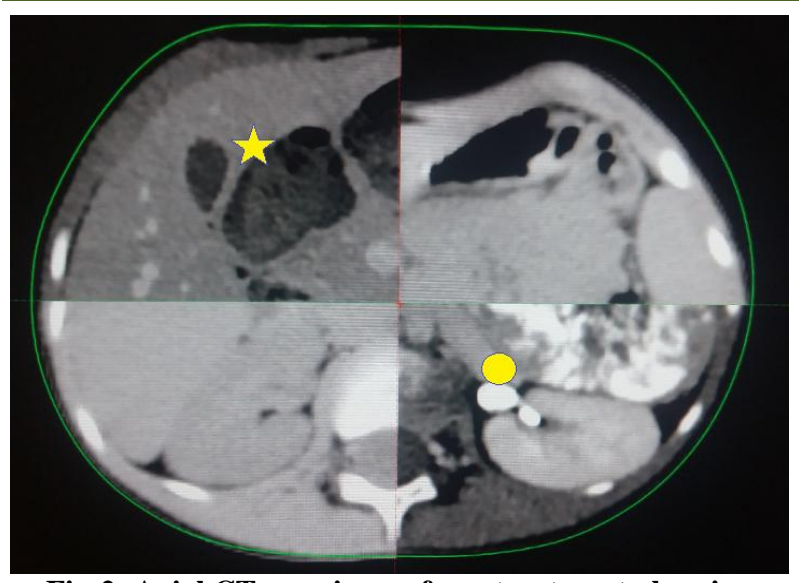

Fig-2: Axial CT-scan image from treatment planning system, showing a registration between simulation CTscan (star) and initial CT-scan (circle)

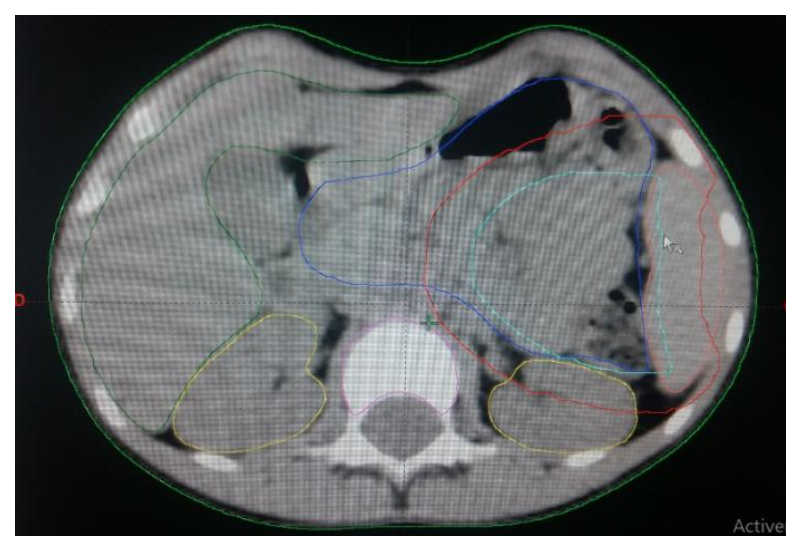

Fig-3: Axial CT-scan image from treatment planning system, showing delineation of clinicql tqrget volume (cyan), planning target volume (red), peritoneal cavity (blue), liver (brown) and kidneys (green)

Radiation therapy by modulation of intensity was used. A dose of 21 Gray (Gy) was prescribed on the PTV, with a fractionation of $1.5 \mathrm{~Gy}$ per fraction either fraction, for a total of 14 fractions. Treatment planning system allows checking dose distribution in target volumes (Figure-4). The treatment was spread over days 18 days. Radiotherapy treatment was well tolerated with only grade 2 gastrointestinal toxicity, nausea type with diarrhea.

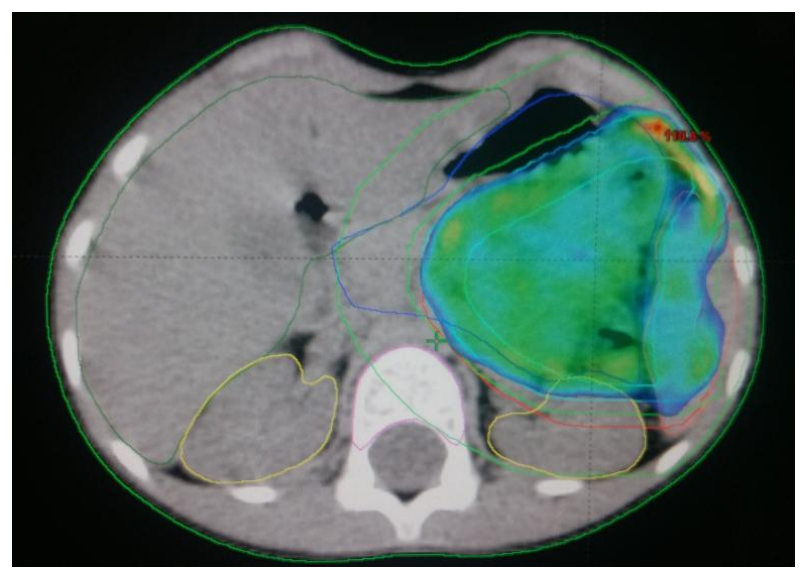

Fig-4: Axial CT-scan image from treatment planning system, showing dose distribution
The child was subsequently given maintenance treatment with isotretinoin for 6 months. With a 15month follow-up, the disease is well controlled both locally and remotely. No late complications from radiotherapy have been reported.

\section{DISCUSSION}

Neuroblastoma (NBL) is the most common extra-cranial solid tumor in children [4], and account for $97 \%$ of all neuroblastic tumors [5]. Neuroblastomas are heterogeneous, varying in terms of location, histopathologic appearance, and biologic characteristics [5].

The International Neuroblastoma Risk Group (INRG) utilizes a classification system that utilizes multiple risk factors to stratify patient's pretreatment. These factors include INRG imaging stage, age, and pathology (histology, differentiation, amplification of MYCN, diploidy, and 11q aberration). The combination of these factors allows a patient to be stratified into the following pre-treatment risk groups: very low, low, intermediate, and high [1].

Patients at the highest risk for disease progression and mortality are those who are older than 18 months of age and have either disseminated disease or localized disease with unfavorable markers such as MYCN amplification. Despite aggressive multimodality therapy, current survival rates remain low (approximately 50 percent) [6], and the improved outcomes have come at a cost of significant early and late toxicity [7].

Improved survival outcomes have been achieved using an aggressive multimodality approach that includes chemotherapy, surgical resection, hematopoietic stem-cell transplantation, radiation therapy, and immunotherapy or cis-retinoic acid [8].

As with other aggressive metastatic cancers, local control of the primary tumor plays an important role for high-risk neuroblastoma, and patients are treated with both surgery and radiation therapy (administered after consolidation chemotherapy). The importance of achieving a gross total resection of the primary tumor in patients with disseminated disease is controversial, with some studies [9], but not others [10, $11]$, suggesting a better outcome for complete resection. Surgical resection of the tumor should be performed by a pediatric surgeon with experience in resecting extensive, infiltrating tumors. Resection should be performed after several courses of induction chemotherapy, when the tumor is smaller and less invasive [8].

Radiation therapy (RT) to the primary tumor bed is recommended for high-risk neuroblastoma and is administered after consolidation therapy in most treatment protocols. Radiation therapy is beneficial in 
preventing local tumor recurrence $[12,13]$. The standard amount of radiation administered is $21 \mathrm{~Gy}$ to the primary tumor bed, as well as radiation to endinduction sites of metastatic disease [14, 15]. Current studies are ongoing, evaluating radiation dose escalation in patients with residual primary tumor and dose de-escalation in patients who had a complete resection of their primary tumor. The few studies evaluating proton radiation therapy have shown that when compared to photon therapy, patients were able to decrease the dosage of radiation to nearby organs without any increase in local recurrence [16]. There is debate about whether the RT field should include lymph nodes adjacent to the primary tumor [13]. Similarly, there is discussion about which metastatic lesions need irradiation, and how this impacts local versus overall relapse risk [17].

The child, subject of this work, received local irradiation with modulation of intensity, after gross total resection and consolidation treatment. The consequences in terms of survival and tolerance are very satisfactory.

\section{CONCLUSION}

Radiotherapy currently has a major place in the local treatment of high-risk neuroblastoma, however several questions remain to be resolved, in particular the prescribed dose at the level of the target volumes, the definition of these target volumes and finally the irradiation technique.

\section{REFERENCES}

1. Cohn SL, Pearson AD, London WB, Monclair T, Ambros PF, Brodeur GM, Faldum A, Hero B, Iehara T, Machin D, Mosseri V, Simon T, Garaventa A, Castel V, Matthay KK, INRG Task Force. The International Neuroblastoma Risk Group (INRG) classification system: an INRG Task Force report. J Clin Oncol. 2009; 27(2):289.

2. Monclair T, Brodeur GM, Ambros PF, Brisse HJ, Cecchetto G, Holmes K, Kaneko M, London WB, Matthay KK, Nuchtern JG, von Schweinitz D, Simon T, Cohn SL, Pearson AD, INRG Task Force. The International Neuroblastoma Risk Group (INRG) staging system: an INRG Task Force report. J Clin Oncol. 2009; 27(2):298.

3. Zage PE, Kletzel M, Murray K, Marcus R, Castleberry R, Zhang Y, London WB, Kretschmar C, Children's Oncology Group. Outcomes of the POG 9340/9341/9342 trials for children with highrisk neuroblastoma: a report from the Children's Oncology Group. Pediatr Blood Cancer. 2008 Dec;51(6):747-53.

4. Brodeur GM, Hogarty MD, Mosse YP. Neuroblastoma. In: Pizzo PA, Poplack DG, editors. Principles and practice of pediatric oncology. 6th ed. Philadelphia: Williams and Wilkins; 2011; 886-922.
5. Goodman MT, Gurney JG, Smith MA, Olshan AF. Sympathetic nervous system tumors. In: Cancer Incidence and Survival among Children and Adolescents: United States SEER Program, 1975-1995, Ries, LA, Smith, MA, Gurney, JG, et al (Eds), National Cancer Institute, Bethesda, MD 1999. p.35.

6. Coughlan D, Gianferante M, Lynch CF, Stevens JL, Harlan LC. Treatment and survival of childhood neuroblastoma: Evidence from a population-based study in the United States. Pediatr Hematol Oncol. 2017;34(5):320.

7. Fischer J, Pohl A, Volland R, Hero B, Dübbers M, Cernaianu G, Berthold F, von Schweinitz D, Simon T. Complete surgical resection improves outcome in INRG high-risk patients with localized neuroblastoma older than 18 months. BMC Cancer. 2017;17(1):520.

8. Pinto NR, Applebaum MA, Volchenboum SL, Matthay KK, London WB, Ambros PF, Nakagawara A, Berthold F, Schleiermacher G, Park JR, Valteau-Couanet D, Pearson AD, Cohn SL. Advances in Risk Classification and Treatment Strategies for Neuroblastoma. J Clin Oncol. 2015;33(27):3008.

9. Holmes K, Pötschger U, Pearson ADJ, Sarnacki S, Cecchetto G, Gomez-Chacon J et al. International Society of Paediatric Oncology Europe Neuroblastoma Group (SIOPEN). Influence of Surgical Excision on the Survival of Patients With Stage 4 High-Risk Neuroblastoma: A Report From the HR-NBL1/SIOPEN Study. J Clin Oncol. 2020;38(25):2902.

10. Simon T, Häberle B, Hero B, von Schweinitz D, Berthold F. Role of surgery in the treatment of patients with stage 4 neuroblastoma age 18 months or older at diagnosis. J Clin Oncol. 2013 Feb;31(6):752-8.

11. Strother D, van Hoff J, Rao PV, Smith EI, Shamberger RC, Halperin EC, Murray KJ, Castleberry RP. Event-free survival of children with biologically favourable neuroblastoma based on the degree of initial tumour resection: results from the Pediatric Oncology Group. Eur J Cancer. 1997;33(12):2121.

12. Pai Panandiker AS, Beltran C, Billups CA, McGregor LM, Furman WL, Davidoff AM. Intensity modulated radiation therapy provides excellent local control in high-risk abdominal neuroblastoma. Pediatr Blood Cancer. 2013;60(5):761.

13. Haas-Kogan DA, Swift PS, Selch M, Haase GM, Seeger RC, Gerbing RB, Stram DO, Matthay KK. Impact of radiotherapy for high-risk neuroblastoma: a Children's Cancer Group study. Int J Radiat Oncol Biol Phys. 2003;56(1):28.

14. Mazloom A, Louis CU, Nuchtern, Kim E, Russell H, Allen-Rhoades W, Krance R, Paulino AC. Radiation Therapy to the Primary and Postinduction Chemotherapy MIBG-Avid Sites in 
High-Risk Neuroblastoma. Int. J. Radiat. Oncol. Boil. Phys. 2014;90:858-862.

15. Casey DL., Kushner BH, Cheung NKV, Modak S, LaQuaglia MP, Wolden SL. Local Control with 21-Gy Radiation Therapy for High-Risk Neuroblastoma. Int. J. Radiat. Oncol. Boil. Phys. 2016;96:393-400.

16. Hattangadi JA, Rombi B, Yock TI, Broussard G, Friedmann AM, Huang M, Chen YL, Lu HM, Kooy H, MacDonald SM. Proton Radiotherapy for High-Risk Pediatric Neuroblastoma: Early
Outcomes and Dose Comparison. Int $\mathbf{J}$ Radiat Oncol Boil Phys. 2012;83:1015-1022.

17. Polishchuk AL, Li R, Hill-Kayser C, Little A, Hawkins RA, Hamilton J, Lau M, Tran HC, Strahlendorf C, Lemons RS, Weinberg V, Matthay KK, DuBois SG, Marcus KJ, Bagatell R, HaasKogan DA. Likelihood of bone recurrence in prior sites of metastasis in patients with high-risk neuroblastoma. Int $\mathbf{J}$ Radiat Oncol Biol Phys. 2014;89(4):839. 